\title{
Explorando los discursos de las organizaciones
}

Daniel Cassany Universitat Pompeu Fabra (Barcelona, España) daniel.cassany@trad.upf.es Sitio personal: http://www.upf.es/dtf/personal/danielcass

Sitio de la red investigación: http://www.upf.es/dtf/xarxa/pral

\begin{abstract}
Resumen. Después de comentar algunas de las orientaciones con que se estudian los discursos en las organizaciones (empresas o instituciones), presentamos dos clasificaciones discursivas, basadas respectivamente en el organigrama (formal / informal, horizontal / vertical, etc.) y en la función comunicativa (discursos técnico-científicos, organizativos, comerciales y protocolarios). También establecemos una tipología de intervenciones lingüísticas en organizaciones, según tomen como objeto de trabajo la estructura organizativa, los recursos humanos, el registro o un discurso particular.
\end{abstract}

Denominaciones actuales como 'español de los negocios', 'lengua con fines específicos (LFE)', 'discursos disciplinarios', 'comunidades discursivas específicas' o ‘comunicación en las organizaciones' se refieren grosso modo a un mismo referente, aunque procedan de disciplinas con propósitos, metodologías y fundamentos diferentes. El interés por los discursos especializados ha surgido y crecido de modo paralelo en las últimas décadas, en la investigación universitaria de orientación lingüística (análisis del discurso, terminología, lingüística aplicada) o político-sociológica (teoría de la organización), en el desarrollo empresarial (búsqueda de calidad, mejora de resultados, formación, etc.) y también en la enseñanza del español (cursos de español comercial, para empresarios, para las relaciones internacionales, etc.). Desgraciadamente, la interacción entre estas distintas orientaciones no es tan frecuente como sería deseable y a menudo cada disciplina ignora los trabajos de sus vecinos. En este artículo nos proponemos contribuir a romper este aislamiento presentando precisamente algunas de estas orientaciones complementarias al 'español de los negocios'.

Partiendo del concepto básico de organización, nos proponemos explorar los discursos verbales que se generan en el sector laboral, en las empresas y las instituciones. Entendemos la organización como una agrupación estructurada de personas que desarrollan actividades específicas para conseguir propósitos que no podrían alcanzarse individualmente; la interacción verbal entre estos individuos es uno de los elementos constitutivos de la organización y una de sus herramientas para conseguir los objetivos. Desde esta óptica, el español de los negocios es la lengua utilizada en los discursos generados en las organizaciones de la comunidad hispanohablante. Preferimos hablar de discursos de las organizaciones que de español de negocios, porque las comunicaciones se materializan en forma de textos orales y escritos y porque se contextualizan en organizaciones particulares —que suelen tener una cultura, unos géneros y un estilo también particulares. Nuestro punto de vista es el del lingüista aplicado —o el mediador lingüístico (Cassany 1996) — que aporta sus conocimientos a las organizaciones para solucionar los problemas comunicativos que padecen, sea con la formación lingüística, la traducción y redacción u otro tipo de intervención.

\section{Orientaciones y líneas de investigación}

Los estudios sobre los discursos en la organización adoptan orientaciones variadas según provengan del mundo empresarial o de la investigación universitaria, de la iniciativa pública o privada, o del campo de las ciencias del lenguaje, de la política o de la publicidad y el márqueting. Desde la sociología y la política, aportan buenas síntesis Ramió y Ballart ed. (1993) o Regouby (1988). En la tradición del análisis del discurso, con un enfoque empírico con el concepto de género como punto de partida, destaca el creciente interés por el análisis de corpus textuales extensos (Hyland 2000), por el estudio de la construcción socio-histórica de los géneros de cada disciplina (Berkenkotter y Huckin 1995; Gunnarsson, Linell y Nordberg 1997), por la implicación entre el discurso oral y las actividades no verbales en el ámbito laboral (Boutet, Gardin y Lacoste 1995) o por la aplicación del aparato teórico del análisis del discurso a los problemas cotidianos (Gunnarsson 1997).

En el ámbito más restringido de la escritura técnica y empresarial, existe una importante e histórica tradición anglosajona de estudios lingüísticos aplicados. En EEUU encontramos varias revistas especializadas (JBTC, TCQ, JTWC), selecciones de artículos (Harkins y Plung ed. 1982) e infinidad de manuales, puesto que las universidades norteamericanas incluyen materias de redacción en la mayoría de los estudios. En Europa destaca el Institute of Scientific and Technical Communication, con su revista Communicator, además del manual teóricopráctico de Turk y Kirkman (1989). 
Dentro del sector público, el denominado movimiento para el lenguaje llano (en inglés Plain Language Movement o Plain English; en España, también conocido como simplificación del lenguaje) ofrece otra orientación sugerente. Con el propósito de mejorar la comunicación entre la ciudadanía y los grupos y las instituciones dirigentes $\longrightarrow$ indirectamente de profundizar en la democracia-, el lenguaje llano audita la legibilidad y comprensibilidad de los textos públicos (jurídicos, administrativos, económicos, etc.), analiza las dificultades lingüísticas que presentan; propone alternativas a la redacción burocrática, etc. Aunque se haya desarrollado básicamente en el mundo anglosajón, (Eagleason 1990; Bailey 1990) empiezan a haber trabajos españoles (MAP 1991; IVAP 1995) ${ }^{\mathbf{1}}$.

Finalmente, en lado más comercial, cabe destacar una prolífica producción de obras ligeras (manuales de autoayuda, recetarios de soluciones y 'confesiones' de famosos empresarios, psicólogos o publicistas), destinados al consumo masivo —que uno encuentra en cualquier librería de aeropuerto. Con una orientación prescriptiva $-\mathrm{y}$ a menudo reduccionista - presentan las 'claves' de un determinado aspecto para conseguir su mejora o comprensión; en el terreno lingüístico abundan manuales para hablar en público, escribir informes técnicos o cartas, manejar emails o elaborar webs (resulta ilustrador pasearse por las webs de editoriales especializadas como www.gestion2000.com o www.e-deusto.com). Son útiles sin ser traducciones inglesas o francesas Delisau (1986), Sanz y Fraser (1998) o Güell y Sanz (2000).

\section{Tipología de textos en la organización}

Una organización reproduce la misma complejidad y diversidad de discursos que encontramos en la vida real, por lo que cualquier aproximación a su estudio debe lidiar con el problema de distinguir los tipos, géneros y registros principales, en una intrincada y heterogénea selva discursiva. Podemos distinguir dos perspectivas en el estudio de la tipología de comunicaciones en las organizaciones: la que parte del organigrama o la estructura organizativa y la que distingue tipos funcionales. Seguimos Cassany (1995) para este apartado.

\section{El organigrama}

La primera dicotomía básica entre comunicación externa e interna distingue los mensajes que se dirigen a destinatarios ajenos a la organización (clientes, proveedores, administración, prensa) como publicidad, correspondencia, comunicados, etc.; de los que se cruzan unidades o áreas de la misma empresa (informes, análisis de contabilidad, proyectos, manuales de procedimientos, normativas, ordenanzas laborales, contratos, revista interna, etc.). Tradicionalmente mereció más interés e inversión la externa, porque es la que ofrece una imagen social del organismo y, en algunos casos, la que vehicula su actividad comercial, pero recientemente el interés por estudiar los procesos organizativos y la necesidad de mejorarlos ha llevado a prestar atención a la interna.

Dentro del grupo interno, distinguimos la comunicación formal de la informal. La primera corresponde a las líneas rectas continuas (en el siguiente cuadro) y deriva del cargo y de la función que desempeña un puesto de trabajo; se trata de intercambios oficiales, periódicos, planificados, etc. (reuniones periódicas, informes, mensajería interna, etc.). En cambio, las líneas onduladas discontinuas corresponden a la interacción informal, impredecible y espontánea que se establece entre las personas que ocupan los puestos de trabajo, por motivo de sus relaciones personales (como conversaciones, rumores, filtraciones, chismorreos, etc.). Así, la reunión semanal de dirección o el informe semestral de cuentas son formales, pero la conversación entre empleados amigos durante el desayuno es informal. En principio, la actividad organizativa se basa en los intercambios formales, aunque recientemente se está reconociendo la aportación relevante de los intercambios informales. La implantación de las nuevas tecnologías (correo electrónico, foros, sitios web, etc.) está borrando la distinción entre ambos tipos y desarrollando sistemas más abiertos, informales y ágiles de comunicación. 


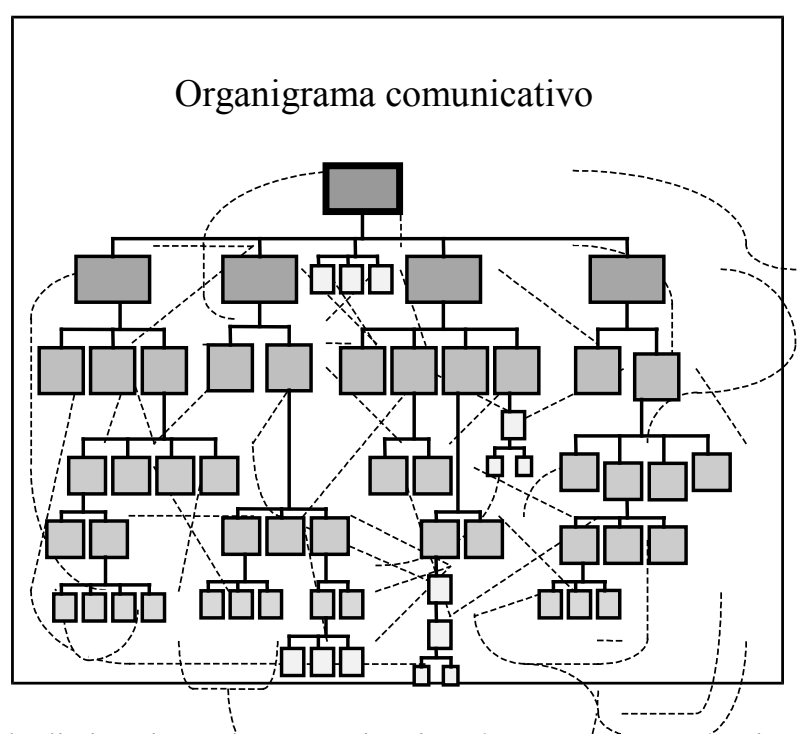

Dentro del grupo formal, distinguimos lą comunicación horizontal, eñntré sujetos o unidades de un mismo nivel jerárquico (entre directivos, especialistas,-operarios)-y-de-perfil profesional parecido, y la vertical, entre sujetos de distinto nivel y perfil (entre técnicos y operarios, directivos y empleados). Esta última incluye el problema de la divulgación de conocimientos técnicos a no especialistas o de establecer comunicación entre grupos con niveles y grados de conocimiento diverso de un mismo tema.

Finalmente, dentro del grupo vertical, distinguimos el mensaje descendente, de la dirección a la base, de la ascendente, de los empleados a la dirección — habitualmente mucho menos desarrollada. Otras distinciones que se usan corrientemente son el parámetro escalar especializada / general y la dicotomía oral / escrita.

\section{Ámbitos comunicativos}

Atendiendo a criterios pragmáticos (función, interlocutores) y discursivos (estructura, estilo) podemos establecer cuatro grandes ámbitos comunicativos en la organización: el técnico-científico, el organizativo, el comercial y el protocolario. No se trata de grupos homogéneos: las fronteras entre si resultan difusas y pueden hacerse varias subdivisiones importantes dentro de cada uno. A grandes rasgos, los dos primeros ámbitos son internos y más especializados, mientras que los segundos tienden a ser externos y generales:

Tipos funcionales de comunicación en la organización

\begin{tabular}{|c|c|c|c|c|}
\hline & Técnico-científico & Organizativo & Comercial & Protocolario \\
\hline$\frac{0}{3} \cdot \frac{0}{3}$ & $\begin{array}{l}\text { Transmitir información } \\
\text { objetiva y precisa. }\end{array}$ & $\begin{array}{l}\text { Ordenar y regular la } \\
\text { actividad de la } \\
\text { organización. }\end{array}$ & $\begin{array}{l}\text { Influir sobre la opinión y } \\
\text { la conducta del } \\
\text { destinatario. }\end{array}$ & $\begin{array}{l}\text { Mantener y consolidar las } \\
\text { relaciones autor-lector. }\end{array}$ \\
\hline 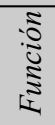 & Referencial. & $\begin{array}{l}\text { Conativa, referencial y } \\
\text { metalingüística. }\end{array}$ & Conativa y referencial. & Expresiva y poética. \\
\hline 六 & $\begin{array}{l}\text { Áreas técnicas de cada } \\
\text { ámbito (proyectos, auditoría, } \\
\text { evaluación, investigación). }\end{array}$ & $\begin{array}{l}\text { Áreas de organización } \\
\text { (dirección, personal, } \\
\text { administración, } \\
\text { evaluación, calidad) }\end{array}$ & $\begin{array}{l}\text { Áreas específicas } \\
\text { (márqueting, publicidad, } \\
\text { comunicación, } \\
\text { comercial, ventas) }\end{array}$ & $\begin{array}{l}\text { Áreas específicas } \\
\text { (comunicación, relaciones } \\
\text { públicas, gabinete personal), } \\
\text { secretarios personales. }\end{array}$ \\
\hline 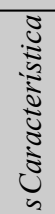 & $\begin{array}{l}\text { Especializada, } \\
\text { despersonalizada, con mucha } \\
\text { terminología, integra } \\
\text { lenguajes semióticos no } \\
\text { verbales (dibujo, cuadro). }\end{array}$ & $\begin{array}{l}\text { Muy estructurada, con } \\
\text { forma directiva } \\
\text { (instrucción, norma, } \\
\text { reglamento). }\end{array}$ & $\begin{array}{l}\text { Versátil, usa técnicas } \\
\text { persuasivas y retóricas. }\end{array}$ & $\begin{array}{l}\text { Personalizada y } \\
\text { individualiza-da; estilo } \\
\text { elegante, cordial y amable; } \\
\text { presentación impecable. }\end{array}$ \\
\hline
\end{tabular}




\begin{tabular}{|c|l|l|l|l|}
\hline$\frac{2}{5}$ & Informes técnicos (física, & Manual de procedimientos, & Publicidad (anuncios, & $\begin{array}{l}\text { Cartas de agradecimiento, } \\
\text { pésame, felicitación; } \\
\text { mailings), } \\
\text { saludas, invitaciones, }\end{array}$ \\
química, economía, & reglamento interno, orde- & auditoría); investigación & nanzas laborales, normas y & correspondencia \\
(artículos en boletines, & protocolos de actuación; & comercial (cartas, \\
congresos); manuales & burocracia; lenguajes \\
técnicos. & facturas); relaciones con & discursos protocolarios. \\
administrativo y jurídico. & los medios. & \\
\hline
\end{tabular}

Los discursos técnico-cientificos exponen datos especializados (con conceptualización controlada, nivel alto de abstracción, densidad terminológica), de manera económica, objetiva y eficaz. Tienen interlocutores cualificados, con formación específica en el campo o tema de comunicación. Presentan secuencias textuales específicas (definiciones, citaciones, enumeraciones, cálculo, razonamientos); tienen modalidad afirmativa; sufren una fuerte despersonalización (verbos impersonales, pasivas, $3^{\mathrm{a}}$ persona del singular), y usan una sintaxis controlada con tendencia a la nominalización. Pueden incluir mapas, gráficos, dibujos, esquemas, fotografías, tablas o símbolos e iconos.

Los discursos organizativos aglutinan las funciones referencial (para describir la realidad organizativa), conativa (para ordenar lo que debe hacerse) y metalingüistica (para explicar conceptos de funcionamiento interno) con el propósito de regular la actividad interna de la organización. Se trata de un ámbito básicamente vertical, escrito, medianamente especializado e interno. Dos subtipos especiales son el lenguaje administrativo y el jurídico —que deben considerarse los discursos organizativos de la Administración Pública. Con un grado de desarrollo muy superior al resto, tienen proyección y bastante influencia en el resto de los ámbitos —puesto que todos pertenecemos a este organismo ${ }^{2}$.

Los discursos comerciales regulan, mantienen y potencian las relaciones comerciales entre la organización y los usuarios, con función referencial y conativa (persuadir al destinatario). Debemos distinguir como mínimo dos grupos importantes: la correspondencia comercial (cartas, pedidos, facturas, albaranes, cheques, etc.) se encarga de regular las transacciones con los clientes actuales; contiene una parte de burocracia administrativa que tiene puntos de contacto con la comunicación organizativa. Por otra parte, la publicidad en sus diversas formas (correspondencia, catálogos, anuncios en los medios, etc.) busca captar nuevos clientes; en los últimos años ha tenido un desarrollo frenético muy por encima del resto de ámbitos, de modo que son los discursos menos fosilizados, los más versátiles y más permeables a todo tipo de influencias (literatura, cine, moda, tradiciones, etc.) y recursos (imágenes, poética, música, humor, sorpresa, etc.).

Finalmente, los discursos protocolarios tienen el objetivo de mantener y consolidar la comunicación entre emisor y receptor, utilizando el componente personal de la relación, la cortesía y la estética (o función expresiva y poética). Son breves, ponen énfasis en la interacción entre autor y lector, en la liturgia ceremonial (tono cordial, amabilidad, formas). Tienen estructuras textuales estereotipadas, formulan explícitamente al emisor $\left(1^{\mathrm{a}}\right.$ persona) y al receptor (usted / ustedes / $t u$, tratamientos honoríficos, evita el sexismo lingüístico); buscan un estilo atractivo (elegante, sin amaneramiento, con toques personales, modalidad variada); usan sintaxis y léxico de la lengua común, y cuidan la presentación (papel, tipografía y formato). Algunos ejemplos son la felicitación de Navidad, la invitación a un acto, la carta de agradecimiento, de pésame, el saluda, el menú gastronómico o la nota que acompaña a un regalo. Gestionan estos textos personas o unidades específicas (relaciones públicas, comunicación, gabinete personal, secretarios, etc.) y se dirigen a clientes, proveedores o colaboradores (comunicación externa, oral o escrita, de tema general).

En conjunto, la organización ofrece una gran diversidad de discursos. Si alguna característica común presenta esa variedad es, sin duda, la de pertenecer a un mismo grupo humano, a una misma comunidad discursiva, que por este hecho comparte una cultura y un estilo comunicativo únicos, que son particulares e irrepetibles.

\section{La intervención en la comunicación}

La enseñanza del español de los negocios pretende sin duda que un individuo pueda participar eficazmente en el entramado comunicativo que hemos esbozado, pero cada destacar que la formación es solo una de las intervenciones que un lingüista aplicado pueda realizar en las organizaciones (Payrató 1996). A continuación presentamos una clasificación de tareas que se puede realizar en una organización para mejorar la calidad de su comunicación. Teniendo en cuenta el foco sobre el que se realiza la actividad, distinguimos: intervenciones sobre la estructura organizativa (reorganización de organigramas, configuración de canales comunicativos o regulación de procesos de producción y recursos informáticos), los recursos humanos (selección, formación y asesoría), el registro (tipos de texto, formularios, manuales de estilo, terminología) y el discurso particular (traducción, interpretación, corrección, etc.): 
Tipología de intervenciones

\begin{tabular}{|c|c|c|}
\hline Ámbito & Tipo & Descripción \\
\hline \multirow{3}{*}{$\begin{array}{l}\text { Estructura de } \\
\text { la } \\
\text { organización }\end{array}$} & $\begin{array}{l}\text { 1. Auditoría } \\
\text { comunicativa }\end{array}$ & $\begin{array}{l}\text { Evaluación de la cultura de la organización, de su calidad comunicativa y de su } \\
\text { documentación escrita. }\end{array}$ \\
\hline & $\begin{array}{l}\text { 2. Procesos } \\
\text { organizativos }\end{array}$ & Evaluación y rectificación de los procesos de producción de documentos. \\
\hline & $\begin{array}{l}\text { 3. Recursos } \\
\text { tecnológicos }\end{array}$ & $\begin{array}{l}\text { Evaluación de los recursos tecnológicos empleados, implantación de nuevas } \\
\text { tecnologías. }\end{array}$ \\
\hline \multirow{4}{*}{$\begin{array}{l}\text { Recursos } \\
\text { humanos }\end{array}$} & $\begin{array}{l}\text { 4. Evaluación de } \\
\text { personal }\end{array}$ & Medición de la capacidad expresiva de un grupo determinado de autores \\
\hline & $\begin{array}{l}\text { 5. Actividades } \\
\text { heterodiridas }\end{array}$ & $\begin{array}{l}\text { Métodos programados y cursos de formación dirigidos por profesorado } \\
\text { especialista. }\end{array}$ \\
\hline & 6. Autoformación & $\begin{array}{l}\text { Desarrollo y uso de sistemas variados de formación autodirigida: centros de } \\
\text { autoaprendizaje, sistemas informáticos de autoacceso, formación a distancia. }\end{array}$ \\
\hline & 7. Asesoría & $\begin{array}{l}\text { Utilización puntual o periódica de la tutoría o asesoría sobre comunicación } \\
\text { escrita y redacción. }\end{array}$ \\
\hline \multirow{3}{*}{ Registro } & 8. Manual de estilo & Fijación de criterios lingüísticos generales para cualquier documentación. \\
\hline & 9. Formulario & Elaboración de un repertorio cerrado de modelos y ejemplos de documentos. \\
\hline & 10. Plantilla & $\begin{array}{l}\text { Definición precisa de las características de un tipo de texto, formulada en un } \\
\text { modelo. }\end{array}$ \\
\hline \multirow{3}{*}{ Discurso } & 11. Supervisión & Evaluación de la calidad general de un documento (puede afectar varios niveles). \\
\hline & 12. Traducción & Reformulación de un original en otra lengua. \\
\hline & 13. Redacción & Elaboración de un documento concreto. \\
\hline
\end{tabular}

La auditoría cultural (núm. 1) diagnostica el conjunto de creencias, comportamientos y actitudes (verbalizados en discursos) que comparten los miembros de una organización y que configura su identidad social: lo que se suele denominar 'cultura de empresa'. Paralelamente, una auditoría comunicativa o lingüística evalúa el discurso global (la suma de todos los mensajes) que genera una organización para determinar su eficacia, su calidad o su grado de adecuación a parámetros preestablecidos. En cambio, la evaluación y mejora de los procesos organizativos o de los recursos tecnológicos son intervenciones menos ambiciosas porque se limitan a ámbitos y elementos particulares, por ejemplo: determinar un canal fijo de comunicación para una nueva actividad o implementar una intranet o un programa de contabilidad nuevo.

Las intervenciones sobre los recursos humanos consisten en la evaluación de sus habilidades lingüísticas y comunicativas para la selección o promoción interna; en el desarrollo de todo tipo de sistemas de formación, y en la creación de sistemas de asesoría comunicativa. En formación, distinguimos las actividades autoformativas (el aprendiz dirige su propio aprendizaje) de las heterodirigidas (un docente o tutor dirige su aprendizaje). Recientemente están adquiriendo relevancia los sistemas de formación no presencial con recursos en línea, auto o heterodirigidos (los conocidos centros o aulas de autoaprendizaje o self-acess center); además del ahorro — ¡es más barato organizar materiales en línea que pagar a un docente!- incrementan la disponibilidad formativa (horarios, diversidad de niveles, no fungibilidad del material, etc.), aunque exigen mucha disciplina y constancia del aprendiz.

Las intervenciones sobre el estilo o registro consisten en regular y estandarizar tanto el denominado corpus lingüístico (criterios lingüísticos, terminología, estructura del documento, fraseología, etc.) como el estatus (función, canal, idioma, tipo de texto, etc.). Según el volumen de tipos de discurso regulados, hablamos de manual de estilo, que establece criterios generales para el conjunto de la organización; formulario, que ofrece ejemplos y modelos de un tipo concreto de texto (cartas, informes, actas, etc.), o plantilla, que hace una propuesta muy detallada (diseño, formato, fraseología, etc.) de un único documento.

La confección de manuales de estilo en grandes organizaciones es una de las intervenciones que ha proliferado en los últimos años en España. Desarrollados a partir de la expansión de los medios de comunicación norteamericanos durante los años 60 y 70, los manuales de estilo en organizaciones no periodísticas fijan normas de uso (¿software o programa, clubs o clubes?, ¿periodización o periodificación; ¿C.I.C., CIC o cic —abreviación de comunicado intercentros-?); unifican el idioma, especialmente en grandes organizaciones repartidas entre distintos países y/o continentes; estandarizan documentos (estructura, contenidos, interlocutores, etc.); contribuyen a la formación continuada del personal, y también consiguen reconocimiento y prestigio social.

Finalmente, las intervenciones sobre un discurso irrepetible son actos individuales de mediación lingüística: se interviene en una situación concreta para transmitir un mensaje a un destinatario determinado. Cabe destacar 
que la supervisión incluye todo tipo de manipulación de documentos: corrección gramatical y tipográfica, reformulación estilística, preparación editorial de originales, etc.

En conjunto, esa variada gama de intervenciones sobre la estructura, los recursos humanos, el estilo o una comunicación ofrece distintas posibilidades de mejora de los discursos en una organización. Obviamente, cada una de esas acciones tiene alcances y metas diferentes: si la redacción o la supervisión de un documento solo permite mejorar la calidad de una situación concreta, un manual de estilo constituye un instrumento potente para incrementar la eficacia del conjunto de comunicaciones de una organización.

\section{Epílogo}

A la luz de los apartados anteriores, la denominación 'español de los negocios' puede esconder aspectos muy diversos. En lo referente a los discursos, podemos encontrarnos con textos comerciales (facturas, publicidad), protocolarios (invitaciones, cartas), organizativos (normas, procedimientos) o técnicos (informes de viabilidad, contabilidad). En lo referente a la intervención, el lingüista puede tener que formar a otras personas, elaborar textos o traducirlos. En todos los casos nos encontramos con un tipo de actividad notablemente particular.

\section{Bibliografía}

Bailey, E. P., Jr. 1990 The Plain English Approach to Business Writing. Nova York: OUP.

Berkenkotter, C. y T. Huckin.

1995 Genre Knowledge in Disciplinary Communication. Hillsdale, NL Lawrence Erlbaum.

Boutet, Josiane; Gardin, Bernard y Michèle Lacoste

1995 'Discours en situation de travail', Langages, 117. Marzo. p. 12-31.

Cassany, Daniel

1995 Intervencions en la comunicació escrita de les organitzacions. Tesis doctoral. Universitat de Barcelona. Microficha.

1996 'La mediación lingüística. ¿Una nueva profesión?', Terminómetro, 62-63. Barcelona: 1996. Reproducido en la red Candidus on line: http://www.revistacandidus.com/secs10/sec aldea.htm

Communicator. For writers, editors, illustrators and publishers in business, industry and research. Institute of Scientific and Technical Communicators. Letchworth, GB: Orbital Press.

Delisau, Sergio

1986 Las comunicaciones escritas en la empresa. Barcelona: De Vecchi.

Eagleason, R. D.

1990 Writing in Plain English. Canberra. Australian Government Publishing Service.

Güell, Helena. Y Glòria Sanz

2000 Com millorar l'atenció al client. Barcelona: Gestió 2000.

Gunnarsson, Britt-Louise

1997 'Análisis aplicado del discurso' En: Van Dijk, Teun A. coord. Discourse as Social Interaction. Discourse Studies: A Multidisciplinary Introduction. Volume 2. Londres: Sage. Versión española: El discurso como interacción social. Estudios sobre el discurso II. Una introducción multidisciplinaria. Barcelona: Gedisa. 2000. 405-441.

Gunnarsson, Britt-Louise; Linell, Per y Nordberg, Bengt coord.

1997 The construction of professional discourse. Londres: Longman.

Harkins, C. y D. L. Plung ed.

1982 A Guide for Writing Better Technical Papers. Nova York: IEEE Press.

Hyland, Ken

2000 Disciplinary Discourses. Social Interactions in Academic Writing. Longman.

IVAP (Instituto Vasco para la Administración Pública)

1995 La mejora de la comunicación entre la Administración y los ciudadanos. Ponencias de las jornadas sobre simplificación del lenguaje. Donostia, 1995 / XI / 22-24.

JBTC. Journal of Business and Technical Communication. Thousand Oaks, CA, EUA: Sage Periodicals Presse. http://www.sagepub.co.uk/frame.html?http://www.sagepub.co.uk/journals/details/j0177.html

TCQ. Technical Communication Quarterly. Rhetoric Department, University of Minnesota: ATTW Association of Teachers of Technical Writing http://www.attw.org

JTWQ Journal of Technical Writing and Communication. Amityville, NY: Baywood Publishing Company, http://www.baywood.com/search/PreviewJournal.asp?qsRecord=19 
MAP (Ministerio para las Administraciones Públicas)

1991 Manual de estilo del lenguaje administrativo. Madrid: MAP.

Payrató, Lluís

1996 De professió, lingüista. Panorama de la lingüistica aplicada. Barcelona: Empúries. Versión española: De profesión, lingüista. Panorama de la lingüistica aplicada. Barcelona: Ariel. 1998.

Ramió, Carles y Xavier Ballart ed.

Regouby, C.

1993 Lecturas de Teoría de la organización. Madrid: MAP.

1988 La communication globale. París: Les Éditions d'Organisation. Versión castellana: La comunicación global. Barcelona: Gestió 2000, 1989.

Sanz, Glòria y Alba Fraser

1998 Manual de comunicacions escrites per a l'empresa. 71 models de consulta. Barcelona: Graó. (con disquete informático de documentos) Versión castellana: Manual de comunicaciones escritas para la empresa. 71 modelos de consulta. Barcelona: Graó. 1998.

Turk, Christopher y John Kirkman

1989 Effective Writing. Improving scientific, technical and business communication. Londres: E.\& F. N. SPON. $2^{\mathrm{a}}$ ed.

\section{Notas}

1. Ver también las páginas web de algunas instituciones públicas sobre lenguaje llano: Plain Language en EUA: http://plainlanguagenetwork.org/Organizations/index.html. Web de la Generalitat de Catalunya en catalán: http://www.gencat.es/justicia/llengua/

2. Por ejemplo, el hábito de redactar las sentencias judiciales de varias páginas con una sola oración repleta de gerundios (considerando, resultando) contagió en épocas remotas al estilo administrativo (instancias, propuestas, etc.), que quizás pretendía así simular más autoridad. ¡Todavía hoy podemos rastrear ese tic en ciertos documentos!

\footnotetext{
Abstract. After making some comments on several approaches to the study of the different kinds of discourse produced in organizations (companies or institutions), we present two classifications of texts, one based on the organization chart (formal / informal, horizontal / vertical, etc.), and the other on the communicative function (technical-scientific, organizational, commercial and formal discourse). We also establish a typology of linguistic interventions in organizations, based on the object of work: organizational structure, human resources, linguistic register or a particular discourse.
} 